\title{
Economic Calculation Forecasting of Tourism: Example from Kazakhstan
}

\author{
Ayagoz Yerzhanovna Zhansagimova ${ }^{1,{ }^{*},}$ Zhamilya Kaspievna Mizambekova ${ }^{2}$, \\ Aliya Sagundukovna Aktymbayeva ${ }^{3}$ and Jannat Muhamedzhanovna Bulakbay ${ }^{1}$ \\ ${ }^{1}$ Eurasian National University, Kazakhstan \\ ${ }^{2}$ Kazakh University of Economy, Finance and International Trade, Kazakhstan \\ ${ }^{3}$ Al-Farabi Kazakh National University, Kazakhstan
}

\begin{abstract}
This article evaluates touristic - recreational potential of Kazakhstan and model of organizational forecast of tourist cluster. Interactions within the cluster lead to the development of new ways to compete and generate an entirely new opportunities to overcome isolation on domestic issues, inertia, inflexibility, and collusion between competitors that reduce or completely block the beneficial effects of competition and the emergence of new firms. Thus, the presence of the cluster allows domestic industry to maintain its advantage, and not give it to those countries that are more inclined to upgrade.
\end{abstract}

Keywords: Tourism, cluster, touristic- recreational resources, structure, innovation, model.

\section{INTRODUCTION}

For a few years, Kazakhstan has held a series of many events such as the OSCE summit of the Islamic Conference, the Asian Games. Thus, it's showing excellent organizational and creative abilities and high scientific potential. International Exhibition, which is symbolic demonstration of technical and technological advances, new ideas and interesting projects that will facilitate the integration of Kazakhstan into the world economy. EXPO - 2017 - Kazakhstan is a huge boost to the future with innovations. As the experience of the past, holding such an exhibition has an enormous impact on the development of cities and countries, where it was held. EXPO 2017 might be proved a truly amazing event in the life of our country. No wonder that now the international community has entrusted Kazakhstan holding the World Expo 2017 in Astana. Our task is to unite and actively prepare our country for this grand international event. I am confident that the exhibition EXPO - 2017 will be a step to innovative and high-tech future of Kazakhstan.

The need to develop non-oil sector, strengthening the competitiveness of domestic products and support of Kazakh producers dictated, first of all, the intention of Kazakhstan in the years to become a member of the World Trade Organization. Further modernization and diversification of the economy as one of the priorities of

*Address correspondence to this author at the Eurasian National University, Kazakhstan; E-mail: ayagoz.zhansagimova@mail.ru the country which mentioned by the President Mr. Nursultan Nazarbayev.

According to him, the main purpose of Innovation Development Strategy is to diversify the economy through the development of competitive industries in the non-oil sectors of the economy and the reduction of economic growth from exports of raw materials. At the 14th plenary meeting of the Foreign Investors Council in November 2005, Nazarbayev stressed that Kazakhstan has formed a system of state development institutions such as the Development Bank, the Investment Fund of Kazakhstan National Innovation Fund, the State Corporation for Export and Investment Insurance, Center Marketing and Analytical Research, Center for Engineering and Technology Transfer [1].

In Kazakhstan, marketing and analytical studies have been conducted by consulting companies JE Austin Associates and the Economic Competitiveness Group to determine the competitiveness of economic sectors of the economy of Kazakhstan and which resulted in the pilot areas were selected [2]. Active development of tourism in the second half of $X X$ century. Its reserves are permanent (continuous) innovation. The stimulating effect on innovation in tourism have a variety of factors [3]:

- New areas of science and technology, the emergence of new technologies;

- Economic and political situation in some regions and countries; 
- Innovations undertaken by international organizations, the rules of economic relations, established by the World Trade Organization, new forms of cooperation, being introduced by the World Tourism Organization, decisions of international or regional tourist organizations, associations, generating new knowledge about the tourist resources in different regions of the globe and information on additional opportunities for tourist travel;

- $\quad$ State laws and other legal acts that determine the economic and political principles of operation of tourism enterprises, including the development of the state concept of tourism development, the adoption of new regulations on the socio-economic issues;

- $\quad$ Changes in the markets: the emergence of new tourist destinations, the disparity of services offered to the needs of travel, changing patterns of demand, the emergence of new demands from consumers for quality tourism product;

- Innovation in the activities of manufacturing industries closely related to the tourism business (transport companies, hotels, recreational facilities, communication facilities, etc.);

- $\quad$ The desire of companies to strengthen market positioning and the struggle for survival;

- Unexpected events that do not depend on the will of the people: environmental and technological disasters, acts of terrorism, and others.

Innovations in tourism are stimulated and in some EU countries. For example, in Italy was adopted a law "About the reform of national legislation of tourism". By this Act tourist enterprises equated to industrial, on them were spread exemptions, deductions, subsidies, incentives and benefits of any kind, which are provided by acting legislative standards for the industrial sector, of course, within the financial capabilities for this purpose. The law is aimed at strengthening the mutual cooperation of various agencies and institutions to pursue a single national policy in sphere of tourism, also to use fully capabilities of entrepreneurship in tourist activities.

Sustainable public funding of research projects, the creation of additional grant funds and support innovation, localization of foreign experience in promoting its development will increase the performance of innovative business activity, which in turn will allow to pass an innovative development and care of the raw material model of the economy [4].

Thus, with the advent of the Single Economic Space appeared huge, new opportunities and therefore participating countries are moving in the right direction for the development of innovative activity of small and medium-sized businesses.

EXPO-2017 - "Energy Future" - will attract the world's best energy-saving technologies, new technology development and use of existing alternative energy sources such as solar, wind, sea, ocean and geothermal waters. The theme of the exhibition is really very important and significant, especially for our country. Modern Kazakhstan - one of the countries with the richest reserves of energy resources. However, oil, gas and coal are exhaustible natural resources. Besides, using of them is fatal to humanity and the environment. There is no doubt that the development of alternative energy sources - the overriding environmental, economic and even political task. Astana can be an effective platform for showcasing the best of world developments and trends in the industry. The exhibition will give a powerful impetus to the system of economic diversification and technological upgrading of production facilities and the scientific base of the country. Energy - a natural source, creates conditions for the stimulation and development of human life. Energy maintains the model of societies and, as a concept, combining many aspects, is intriguing questions concerning the universe and humanity in particular. Public access to energy directly determines the specific scenario of their social, economic and environmentally sustainable development. Research and advances in technology related to the optimization of various energy sources, determine the functional approaches communities and create sustainable energy perspective [5]. Since 1851, when London hosted the first World Industrial Exhibition. International Exhibition EXPO acquired every year more and more popularity. It gives everyone a unique opportunity to get acquainted with the economic, technological and cultural achievements of the world. Trade shows are also a kind of platform for the exchange of innovative ideas and convincing demonstration of the possibility of a collective view of the future. The project "Energy Future " sets specific goals is to investigate the strategies, programs and technologies aimed at the development of sustainable energy sources, improving the reliability and efficiency 
of energy supply, promote the use of renewable energy sources and show visitors the need for their active participation in the development and implementation of the plan of energy saving and efficient production use of energy resources.

\section{LITERATURE REVIEW}

Among the works of foreign authors, which addresses a wide range of issues related to the management of innovative development, it should be noted scientific works A.I. Anchishkina, I.A. Blanka V.G. Zinov, D.S. Lviv, E.B. Lenchuk and Z.F. Mazur. V.G. Medinskaya, E.M. Mirsky, Y.P. Morozov, B.A. Raizberg, T.D. Shebeko and a number of other scientists and experts.

The most complete cluster theory is presented in the work of american scientist M.Porter. Among other foreign researchers can distinguish scholarly works of A. Marshall, E. Bergman, E. Fazer, S. Rosenfeld, E. Dakhmen, J.A. Tolenado, D. Sole, M. Enwrite etc.

As for the term "innovation", it is understood by researchers in different ways. There are four areas of understanding innovation [6]:

- $\quad$ Change (F. Valenta, L. Voldachek, Y. Yakovets etc.)

- The final result (N.N. Molchanov, L.M. Hochberg, L. Utkin, S.Y. Glazyev, D.V. Sokolov, V.N. Archangel, R.A. Fatkhutdinov, V.N. Gunin, A.B. Krutik, S.D. Il'enkov G.S. Hamidov, G.D. Kovalev, etc.);

- $\quad$ Progress (V.N. Lapin, A. Twiss, B. Santo, S.V. Valdaypev, F.F. Soulless, G.A. Smirnov, A.B. Titov, V.P. Vorobyev, etc.);

- $\quad$ A set of measures (F. Nixon).

Recently dominant idea of innovation as the end result of innovation, as well as the process of its implementation.

\section{METHODOLOGY}

The phenomenon of the cluster as an object of economic agglomeration of interconnected companies in a certain territory, known since the days of handicraft production. But only since the last quarter of $X X$ century, industrial clusters have begun to show itself as an important factor in regional economic development. Among the economists in the world is becoming increasingly recognized view that the regions in which clusters are formed, are leaders in economic development $[7,8,9]$.

That's why we must first examine past experiences, to relate it to the present, to become an expert in our field, and only then begin to incarnate new ideas and innovations. Tourist activity is based on a foundation of accumulated knowledge's. One sign of success in the market is increasing of market share. Searches are show that not advertising and actively promoting of the product provide a steady growth of market share, but the innovation in all areas of tourist activity does. Innovation processes take place in international and national control systems of tourist activity, the development of new technologies (e-commerce, the creation of virtual travel agencies); forms of marketing, creating a tourist product [8].

Theoretical and methodological basis of the research were modern scientific concepts of economic theory, the theory of innovation and management theory, the fundamental works of Russian and foreign scholars devoted to the study of strategic management, innovation management, the fundamental scientific principles of the regional economy, the cluster theory of innovation and innovation, research domestic and foreign scientists, set out in the periodical literature, proceedings of scientific conferences, theses and monographs, revealing patterns of innovation areas at the regional level.

\section{RESULTS}

Tourism is an important component of economic and social life for a growing number of countries. By its proportion and complexity, tourism entails a large natural, human and material potential, having profound implications on the dynamics of economy and society, on international relationships.

Beerli and Martin (2004) categorized attributes into nine dimensions [9]:

(1) Natural resources (i.e. weather, temperature, rainfall, hours of sunshine, beaches, quality of seawater, length of beaches, overcrowding of beaches, wealth of countryside, protected natural reserves, lakes, mountains, deserts, variety and uniqueness of flora and fauna);

(2) Tourist leisure and recreation (i.e. accommodation, number of beds ,categories, quality, restaurants number, quality, bars, discos 
and clubs, hotels and self-catering, ease of access, excursions at destination, tourist centers and network of tourist information);

(3) Natural environment (i.e. beauty of the scenery, attractiveness, cleanliness, overcrowding, air and noise pollution and traffic congestion);

(4) General infrastructure (i.e. development and quality of roads, airports and ports, private and public transport facilities, development of health services, development of telecommunications, development of commercial infrastructure, extent of building development);

(5) Culture, history, and art (i.e. festival, concerts, handicraft, gastronomy, folklore, religion, museums, historical buildings, monuments, customs and ways of life);

(6) Social environment (i.e. quality of life, underprivileged and poverty, language barriers, hospitality and friendliness of the local residents);

(7) Tourist infrastructure (i.e. accommodation, number of beds ,categories, quality, estaurants number, quality, bars, discos and clubs, hotels and self-catering, ease of access, excursions at destination, tourist centers, network of tourist information);

(8) Political and economic factors(i.e. political stability, political tendencies, terrorist attacks, safety, crime rate, economic development and prices);

(9) Leisure and recreations (i.e. golf, fishing, hunting, skiing, entertainment and sports activities, scuba diving, trekking, adventure activities, theme parks, water parks, zoos, casino.

The founder of the theory of cluster development is M. Porter, who has studied this problem by examining the competitive position of more than 100 branches in the different countries. M. Porter pointed out that the most competitive on an international scale the same industry firms usually do not haphazardly scattered in various developed countries, and tend to concentrate in the same country, and sometimes even in the same region of the country $[10,895 p]$.

The founder of the theory of cluster development is M. Porter, who has studied this problem by examining the competitive position of more than 100 branches in the different countries. M. Porter pointed out that the most competitive on an international scale the same industry firms usually do not haphazardly scattered in various developed countries, and tend to concentrate in the same country, and sometimes even in the same region of the country [11].

Formation of conditions to create competitive tourism services, assumes conduction of complex research of specifics of tourism organization in Kazakhstan, that will allow to segment the regional tourism market depending on specifics of consumer demand, will substantiate the directions in investment towards development of tourism objects and infrastructure, and will also make prognosis of anthropogenic load over natural objects and landscape complexes of the region [12].

According to the plan of regression analysis towards effectiveness of organization of tourism activity, evaluation procedure assumes consecutive realization of three stages [13]:

1. Formation of analytical base of evaluation indicators (original data).

2. Identification of dependency between major resulting indicator and the indicators characterizing parameters of tourism service.

3. Prognosis of resulting indicator taking into account average year indicators.

Table1: Data to Build Regression Model

\begin{tabular}{|c|c|c|c|c|c|}
\hline End of period & X4 & X3 & $\times 2$ & $\mathrm{X} 1$ & $\mathbf{Y}$ \\
\hline 2009 & 26,6 & 1007 & 1965 & 542 & 40414 \\
\hline 2010 & 23,5 & 1163 & 1801 & 474 & 50559 \\
\hline 2011 & 20,4 & 1203 & 1545 & 347 & 48309 \\
\hline 2013 & 21,3 & 1252 & 1817 & 459 & 58262 \\
\hline 2014 & 23,4 & 1515 & 2017 & 602 & 63136 \\
\hline
\end{tabular}


Let's take statistical indicators of tourism sector in Kazakhstan as the initial data: X1-visitors that were serviced by touristic firms, in mln. people; X2- visitors that were serviced in places of accommodation, in $\mathrm{mln}$. people; X3- quantity of touristic firms; X4- hotel filling in, in \%; Y- service volume that is provided to tourists, in mln.tenge (which is considered as resulting indicator).

Data calculation based on given statistics is provided in table.

Building regression model with the help of Microsoft Excel:

$b_{1}=-55,3$

$b_{2}=60,4 ;$

$b_{3}=26,3 ;$

$b_{4}=-2767,7$;

$Y=-2767,7 x_{4}+26,3 x_{3}+60,4 x_{2}-55,3 x_{1}$

Coefficient of determinacy of the model R, according to Microsoft Excel, is equal 0,999, therefore the model is fully explaining the provided data.

Calculation show that most of all the result is being influenced by $x 1$ indicator (number of visitors), because it has the highest coefficient. Therefore the main factor that can increase the profit of tourism sector in Kazakhstan is increasing the number of visitors, and therefore we need to develop advertisements, marketing, and cluster zones, that will be able to attract a lot of visitors because of it's well known image.

This suggested model can be used to prognoses the profit in 2015. According to assumption about continuation of present tendencies, due to statistical data in 2014 there are going to be the following changes in indicators:

X1- growth by $15,6 \%$ in visitors number that are being serviced by touristic firms (linear trend equation that shows dependency of the indicator upon year, $y=11,36 x+448,62)$;

X2- growth by $8,8 \%$ in visitors number that were serviced in places of accommodation (linear trend equation that shows dependency of the indicator upon year, $y=12 x+1793$ );

X3- growth in quantity of touristic firms by $(1515 / 12,52)-100=21 \%$ (linear trend equation that shows dependency of the indicator upon year, $y=5,3 x+36,2$ );

X4- growth in hotel filling in by $1,1 \%$ (linear trend equation that shows dependency of the indicator upon year, $y=0,38 x+24,66$ assumes a tendency for small fall, nevertheless according to the dynamics of the last years let's assume that the same small growth will continue as this year).

Gathering new meanings of the indicators and prognosis of service volume, which is:-2767,7 * $23,4 * 1,156+26,3 * 1515^{*} 1,21+60,4 * 2017 * 1,088$ $55,3 * 602 * 1,1=69272,351 \mathrm{mln}$. tenge.

On the basis of the results of regression analysis, author has developed organizational structure of the cluster that most fully responds to the requirements in Kazakhstan, conditions and goals of tourism sector development in RK.

The suggested structure reflects the system of cooperation between suppliers and consumers of touristic services (picture 1). The central management body of the cluster is Coordination council. It has the following functions:

- Identification of the goal indicators in development of the cluster,

- Evaluation of intermediate results in accordance with the goal indicators,

- Developing and taking actions to support the members of the cluster,

- Realization of investment and research projects.

Cluster management body is responsible for informing, in a timely manner, all participants about perspective development directions of the cluster, also about potential and material technical resources of scientific and educational institutions with the aim of realization of mutual projects. In order to represent the interests of the participants and to provide guarantees cluster management body must provide standard way of forming contract relationships and realization of mutual projects in spheres of development, production and realization of the products $[14,15]$.

Tourism clusters are formed on the basis of tourism assets in the region and consists of enterprises of different sectors related to the servicing of tourists, for example, tourist operators, hotels and catering sector, 
producers of souvenirs, transportation companies and others. The purpose of creating of the tourism cluster to improve the competitiveness of the territory of the tourist market through synergies, including improving the efficiency of enterprises and organizations belonging to the cluster, stimulating innovation, promoting the development of new directions [16].

Definition of species, specific resources determine the demand for tourism products and indirectly - on the formation and maintenance of the entire tourist infrastructure. Identification of the tourist resources allows for determination necessary elements for the cluster.

\section{REFERENCES}

[1] Material Name / Statistical Handbook: Tourism in the Republic of Kazakhstan for 2007-2012. - Astana 2013.

[2] Porter. M international competition. - Moscow.: International Relations. Moscow, 1993; -895 p.

[3] Marshall, Alfred. Industry and Trade. 3ded. London: Macmillan, 1920.

[4] Peter F. Drucker. Challenges of Management in the XXI century: [trans. from english.] / Peter F. Drucker. - M.: The Publishing office "Williame", 2003.

[5] The Global Innovation Index 2013: The Local Dynamics of Innovation. / EditorsSoumitra Dutta, Bruno Lanvin. -Cornell University, INSEAD, and WIPO, 2013.

[6] Innovation Management / \{S.D. Ilyenkova, L.M. Gohberg, S.U. Yagudin etc edited by Professor. S.D. Ilyenkova. - M.: Unity-Dana, 2003.
[7] Khodadadi, M. What is in a Name? Evoking Associations in Cultural Tourism Marketing of 'Persia' and 'Iran'. PhD Networking Conference, Exploring Tourism III: Issues in PhD Research, 1-2 July 2009, Nottingham University Business School, Nottingham, UK. (2009). p-89

[8] Chernoutsan EM The poles of competitiveness as a key instrument for the implementation of the new industrial policy and regional policy in France / public policy for regional development of Russia. All-Russian Scientific Conference. London: Centre for problem analysis and public management of design, 2008.

[9] Beerli, A. and Martin, J. D. 2004 "Factors influencing destination image". Annals of Tourism Research, 31(3): 657681.

http://dx.doi.org/10.1016/j.annals.2004.01.010

[10] Porter. M international competition. - Moscow.: International Relations. Moscow, 1993. - 895 p.

[11] Sokolenko SI Systems of industrial globalization: Webs. Alliances. Partnership. Clusters. - Kiev. - 2002 -. 645 p.

[12] P. Vorobiev, the formation can withstand the competition of industrial clusters in the regions: a model of organization and political tools / / Center for Regional Economic Research Department of Economics of the Urals State University. Ekaterinburg, 2011.

[13] Material Name / Site Name / / www.stat.kz / digital / Turizm / Pages / default.aspx, Astana 2012

[14] Karmyshev YA Innovative type of development as a factor of social and economic dynamization processes / YA Karmyshev / / Proceedings of the Department of Economic Theory TSU them. GR Derzhavina.Vyp. 1. / Ch. Ed. VM Yuriev. - Tambov: Izd TSU them. GR Derzhavin, 2002.

[15] Castells, M. The Information Age: Economy, Society and Culture. / Per. English. Ed O. Shkaratan. Moscow. - 2000. P.48.

[16] Bezdudny FF, GA Smirnov, Nechaev OD The nature of innovation and its classification / / Innovations. Moscow 1998. - № 2-3. with. 3-13.

\section{DOI: http://dx.doi.org/10.15377/2409-5710.2015.02.01.1}

(C) 2015 Zhansagimova et al.; Avanti Publishers.

This is an open access article licensed under the terms of the Creative Commons Attribution Non-Commercial License (http://creativecommons.org/licenses/by-nc/3.0/) which permits unrestricted, non-commercial use, distribution and reproduction in any medium, provided the work is properly cited. 